\title{
Morning cortisol is lower in obese individuals with normal glucose tolerance
}

This article was published in the following Dove Press journal:

Diabetes, Metabolic Syndrome and Obesity:Targets and Therapy

6 September 2011

Number of times this article has been viewed

\author{
Edavan P Praveen' \\ Jaya Prakash Sahoo' \\ Bindu Kulshreshtha ${ }^{2}$ \\ Madan L Khurana ${ }^{3}$ \\ Nandita Gupta' \\ Sada Nand Dwivedi ${ }^{3}$ \\ Guresh Kumar ${ }^{3}$ \\ Ariachery C Ammini' \\ 'Department of Endocrinology, \\ All India Institute of Medical Sciences, \\ ${ }^{2}$ Ram Manohar Lohia Hospital, \\ ${ }^{3}$ Department of Biostatistics, \\ All India Institute of Medical Sciences, \\ New Delhi, India
}

Correspondence: AC Ammini

Head, Department of Endocrinology,

All India Institute of Medical Sciences,

New Delhi-29, India

Tel +9 | I I 26593645

Fax +9| || 26589|62

Email aca433@yahoo.com
Background: There is no consensus on the role of cortisol in the pathogenesis of obesity and metabolic syndrome (MS). This cross-sectional study aimed to analyze the relationship of morning plasma cortisol and adrenocorticotropic hormone (ACTH) levels with body mass index (BMI) and glucose tolerance.

Subjects and methods: The sample frame was the "Offspring of individuals with diabetes study" database. A total of 358 offspring of individuals with type 2 diabetes mellitus (T2DM) and 287 individuals without a known family history of T2DM were recruited for the study. Subjects who were $\geq 10$ years of age were selected from the database for analysis. Subjects with T2DM were excluded. All participants underwent a $75 \mathrm{~g}$ oral glucose tolerance test (OGTT), and blood samples were collected at 0, 30, 60, and 120 minutes for glucose, insulin and C-peptide. Plasma cortisol, ACTH, and lipid profile were estimated from the fasting sample.

Results: Four hundred and ninety-five participants (305 males [62\%] and 190 females [38\%]) were included in the analysis. ACTH and cortisol levels were higher in normal-weight subjects than in overweight/obese subjects. Both ACTH and cortisol increased as fasting plasma glucose increased. Cortisol levels were significantly lower in offspring of T2DM subjects with MS than in offspring of T2DM subjects without MS. When adjusted for BMI, the significance was marginal. In males, cortisol levels were negatively correlated with early insulin secretion during OGTT (insulinogenic index [0-30]) and positively with waist circumference and serum high-density lipoprotein cholesterol. In females, fasting glucose and systolic blood pressure were significantly and positively correlated.

Conclusion: Body weight was correlated negatively with morning plasma cortisol and ACTH, whereas fasting glucose was correlated positively.

Keywords: cortisol and body weight, cortisol and obesity, cortisol and glucose tolerance, ACTH, cortisol, metabolic syndrome

\section{Introduction}

Central adiposity, hepatic steatosis, dyslipidemia, muscle wasting, pancreatic beta-cell dysfunction, and glucose intolerance are features of chronic glucocorticoid excess. ${ }^{1,2}$ Many of these features are also observed in patients with prediabetes and metabolic syndrome (MS). There is speculation on the possibility of subtle abnormalities of cortisol biosynthesis/metabolism in the pathogenesis of MS. ${ }^{3,4}$ Some reports have documented higher plasma cortisol in MS patients than in healthy subjects. ${ }^{5-7}$ However, the relationship between different MS components and serum cortisol is not consistent. Some studies have found no association between waist circumference (WC) and cortisol in overweight youth, ${ }^{6}$ whereas others have reported a positive association with WC. ${ }^{8,9}$ 
The metabolic clearance of cortisol is increased in obese individuals which could obscure the underlying positive association between plasma cortisol and the features of MS. ${ }^{10}$ Reynolds et al observed higher plasma cortisol in glucose-intolerant subjects than in healthy controls. ${ }^{11}$ Here we report our observations from a cross-sectional study on morning plasma cortisol and its relationship with obesity and glucose tolerance.

\section{Subjects and methods}

Our sampling frame was the "Offspring of individuals with diabetes study" database. ${ }^{12}$ There were 358 offspring of individuals with type 2 diabetes mellitus (T2DM) and 287 controls (individuals who did not have a family history of T2DM) recruited for the study. The participants were of Indian origin with age ranging from 5 to 55 years. Index cases with diagnosed T2DM were identified from the endocrine clinic of our hospital and their children and grandchildren were invited to participate. Subjects who were pregnant, lactating, or on medication for any chronic illness were excluded. Subjects without a family history of T2DM were recruited from the general population and the exclusion criteria were the same as above.

From this database, only subjects aged $\geq 10$ years were selected for the analysis (the International Diabetic Federation [IDF] criteria for MS are applicable to children $\geq 10$ years of age). ${ }^{13}$ Subjects who had T2DM were also excluded from the analysis. Details of medical history were collected; a physical examination including anthropometry was performed. For the oral glucose tolerance test (OGTT), subjects were advised to have a normal diet and abstain from alcohol for 3 days prior to the test. After 10-12 hours of overnight fast, $75 \mathrm{~g}(1.75 \mathrm{~g} / \mathrm{kg}$ body weight for children, with a maximum dose of $75 \mathrm{~g}$ ) OGTT was performed. Blood samples were collected before (timing between 8.45 am and $9.30 \mathrm{am}$ ) and at 30,60, and 120 minutes after oral glucose. The samples were collected in EDTA vials under cold conditions. The fasting sample was used for adrenocorticotropic hormone (ACTH), cortisol, and lipid profile estimation. Plasma glucose, insulin, and $\mathrm{C}$ peptide were measured at all time points. Glucose tolerance was classified as per American Diabetic Association 2003 criteria. ${ }^{14}$ Body mass index (BMI) of 25 to $29.9 \mathrm{~kg} / \mathrm{m}^{2}$ was taken as overweight and $\mathrm{BMI} \geq 30$ as obese. For subjects up to 18 years of age, cutoffs recommended by the International Obesity Task Force were used..$^{15} \mathrm{MS}$ was determined by the IDF criteria. ${ }^{13,16}$

WC was measured midway between the lowest rib and the superior border of the iliac crest with an inelastic measuring tape. The hip circumference was measured at the greatest posterior protuberance of buttocks with the subject standing erect, feet together. Blood pressure was measured in sitting position in the left arm with OMRON electronic apparatus (Omron Health Care, Kyoto, Japan), after 10 minutes of rest.

ACTH and cortisol were measured by electro-chemiluminescence assay by ELECSYS 2010 (Roche Diagnostics, IN). The intra-assay coefficient of variation (CV) for cortisol was $3.8 \%$ and the inter-assay CV was $4.2 \%$. For ACTH these CVs were $7.5 \%$ and $8.5 \%$, respectively. Plasma insulin and C-peptide were also measured by electro-chemiluminescence assay. This assay uses monoclonal antibodies against insulin and has $0.05 \%$ cross-reactivity with human proinsulin and its split forms. Intra-assay CV for insulin was 5.1\% and interassay CV was 5.7\%. For C-peptide intra-assay CV was 3.9\% and inter-assay $\mathrm{CV}$ was $3.9 \%$.

Plasma glucose was assayed by glucose oxidase method, on a Labmate 20 Analyser (Trivitron Diagnostics, Chennai, India). Serum triglycerides (TG) and total cholesterol were measured by enzymatic methods. Serum high-density lipoprotein (HDL)-cholesterol was measured after precipitation of chylomicrons, and very-low-density lipoprotein-cholesterol fraction and low-density lipoprotein (LDL) fractions by phosphotungstic acid and magnesium chloride. HDLcholesterol remains in the supernatant after centrifugation, and is measured by the enzymatic cholesterol method. LDLcholesterol was calculated from data of the above parameters by Friedewald's equation. Intra-assay CVs for total cholesterol, TG, and HDL-cholesterol were $1.9 \%, 1.9 \%$, and $4.5 \%$, respectively, whereas inter-assay CVs were $2.5 \%, 2.7 \%$, and $4.9 \%$, respectively. The area under the curve (AUC) during the OGTT was calculated according to Tai's method. ${ }^{17}$ AUC of C-peptide (0-30 minutes) was divided by AUC of glucose (0-30 minutes) to determine the insulinogenic index (0-30). HOMA-IR (homeostasis model assessment-insulin resistance) was measured as proposed by Matthews et al. ${ }^{18}$

\section{Statistical analysis}

Statistical analysis was done using SPSS version15 software (Lead Technologies, Lead, US). The continuous data were expressed as mean $\pm \mathrm{SD}$. Log transformation was also applied to skewed data for ACTH, cortisol, insulin, C-peptide, HOMA-IR, TG, and insulinogenic index (0-30). Student's unpaired $t$-test was used to compare two groups. Analysis of variance (ANOVA) was used to compare quantitative variables when the numbers of groups was $>2$. General linear model was used for comparing groups after adjusting for confounding variables. The correlation between morning cortisol and other parameters was estimated by Pearson's 
correlation method. Partial correlation was performed to adjust for confounding variables such as age and BMI. Tests were considered significant at $P<0.05$.

\section{Results}

Six hundred and forty-five subjects participated in the study and underwent OGTT. Ten subjects with newly diagnosed T2DM were excluded from the analysis; 17 subjects were excluded as they were $<10$ years of age; 618 subjects fulfilled the inclusion criteria; and 495 subjects, for whom complete data were available for ACTH and cortisol, were included in the analysis. There were 305 (62\%) males and 190 (38\%) females. There were 441 (89\%) subjects with normal glucose tolerance, 20 (4\%) with impaired fasting glucose, and 34 (7\%) subjects with impaired glucose tolerance. Three hundred and fifty-eight (72\%) subjects were of normal weight, 93 (19\%) were overweight, and 44 (9\%) were obese.

Cortisol and ACTH levels were higher in males $(r=-0.09$, $P=0.04, r=-0.29, P<0.001$, respectively) than in females Morning plasma cortisol and age were positively correlated ( $r=0.101, P=0.045)$. To check the effect of fasting blood glucose on morning plasma cortisol, we analyzed cortisol levels in different fasting glucose categories in normal and overweight subjects. Details are given in Table 1.

There was a rising trend for ACTH and cortisol with higher fasting blood glucose irrespective of the body weight of subjects. At each fasting glucose category, cortisol levels were higher in normal-weight subjects than in overweight subjects.

Cortisol levels were significantly higher in subjects with impaired fasting glucose (13.8 vs $11.1 \mathrm{ng} / \mathrm{mL}, P=0.04$ ) than in normal glucose-tolerant (NGT) subjects. Among NGT subjects, cortisol and ACTH levels were significantly higher in normal-weight subjects than in subjects who were overweight (for cortisol $11.4 \pm 4.7$ vs $10.4 \pm 4.4, P=0.05$, and for ACTH, $26 \pm 21$ vs $20 \pm 18 \mathrm{pg} / \mathrm{mL}, P=0.002)$.

There were 77 (15.5\%) subjects who fulfilled the IDF criteria for MS. Among normal-weight subjects there was no significant difference in plasma ACTH and cortisol between those with and without MS. Among overweight/obese subjects, cortisol levels were lower in those with MS, but did not reach statistical significance compared with overweight/ obese subjects without MS $(9.6 \pm 4.3$ vs $11 \pm 4.9)$. We performed a subgroup analysis after dividing the subjects into four groups, ie, offspring of T2DM subjects with and without MS, and negative family history of T2DM with and without MS (Table 2). Cortisol levels were significantly lower in subjects with MS and family history of T2DM than in offspring of T2DM subjects without MS. When adjusted for BMI, there was borderline significance between the groups $(P=0.06)$.

Correlations of morning plasma cortisol with MS components and other cardiovascular risk factors were performed separately for males and females. In males, cortisol was negatively correlated with WC, fasting insulin, HOMA-IR,

Table I Plasma ACTH and cortisol levels in normal-weight and overweight subjects in different fasting glucose categories

\begin{tabular}{|c|c|c|c|c|c|c|}
\hline & \multirow{2}{*}{$\begin{array}{l}\text { Glucose } 0 \mathrm{~min} \\
\leq 80 \mathrm{mg} / \mathrm{dL}\end{array}$} & \multirow{2}{*}{$\begin{array}{l}\text { Glucose } 0 \mathrm{~min} \\
80.1-90 \mathrm{mg} / \mathrm{dL}\end{array}$} & \multirow{2}{*}{$\begin{array}{l}\text { Glucose } 0 \mathrm{~min} \\
90.1-100 \mathrm{mg} / \mathrm{dL}\end{array}$} & \multirow{2}{*}{$\begin{array}{l}\text { Glucose } 0 \mathrm{~min} \\
100.1-125 \mathrm{mg} / \mathrm{dL}\end{array}$} & \multicolumn{2}{|l|}{$P$ value } \\
\hline & & & & & Unadjusted & $\begin{array}{l}\text { Adjusted for } \\
\text { age, gender }\end{array}$ \\
\hline \multicolumn{7}{|l|}{ Normal weight } \\
\hline $\mathrm{n}$ & 73 & 176 & 97 & 12 & - & - \\
\hline Age (years) & $21.9 \pm 7.8$ & $24.9 \pm 8.0$ & $25.9 \pm 9.7$ & $31.3 \pm 10.1$ & 0.001 & - \\
\hline BMI $\left(\mathrm{kg} / \mathrm{m}^{2}\right)$ & $20.1 \pm 3.2$ & $20.6 \pm 3.1$ & $20.6 \pm 2.8$ & $22.7 \pm 2.0$ & 0.04 & 0.500 \\
\hline ACTH $(\mathrm{pg} / \mathrm{mL})$ & $20.0 \pm 15.5$ & $24.5 \pm 19.6$ & $33.8 \pm 26$ & $31.0 \pm 21$ & $<0.001$ & 0.003 \\
\hline Cortisol (ng/mL) & $10.9 \pm 4.4$ & $11.3 \pm 4.9$ & $12.0 \pm 5.0$ & $14.9 \pm 4.7$ & 0.050 & 0.163 \\
\hline \multicolumn{7}{|c|}{ Overweight/obese } \\
\hline $\mathrm{n}$ & 26 & 55 & 39 & 17 & - & \\
\hline Age (years) & $26.2 \pm 10$ & $31.7 \pm 11$ & $30.3 \pm 11$ & $32.2 \pm 11$ & 0.20 & - \\
\hline BMI $\left(\mathrm{kg} / \mathrm{m}^{2}\right)$ & $28.1 \pm 2.6$ & $28.7 \pm 3.3$ & $29.9 \pm 5.0$ & $29.6 \pm 4.3$ & 0.30 & - \\
\hline ACTH (pg/mL) & $16.6 \pm 15$ & $19.0 \pm 19$ & $24.3 \pm 18$ & $23.1 \pm 13$ & 0.14 & 0.32 \\
\hline Cortisol (ng/mL) & $10.1 \pm 4.5$ & $10.4 \pm 4.6$ & $10.7 \pm 5.0$ & $10.9 \pm 4.9$ & 0.80 & 0.79 \\
\hline \multicolumn{7}{|l|}{ Overall } \\
\hline $\mathrm{n}$ & 99 & 231 & 136 & 29 & - & \\
\hline Age (years) & $23.0 \pm 8.7$ & $26.6 \pm 9.6$ & $27 \pm 10.3$ & $31.9 \pm 10.7$ & $<0.001$ & - \\
\hline BMI $\left(\mathrm{kg} / \mathrm{m}^{2}\right)$ & $22.2 \pm 4.7$ & $22.6 \pm 4.7$ & $23.4 \pm 5.5$ & $26.8 \pm 4.9$ & $<0.001$ & - \\
\hline ACTH (pg/mL) & $19.1 \pm 15$ & $23.2 \pm 20$ & $31.1 \pm 24.5$ & $26.3 \pm 17$ & $<0.001$ & 0.001 \\
\hline Cortisol (ng/mL) & $10.7 \pm 4.4$ & $\mathrm{II} . \mathrm{I} \pm 4.8$ & $11.6 \pm 5.1$ & $12.6 \pm 5.2$ & 0.236 & 0.434 \\
\hline
\end{tabular}

Abbreviations: ACTH, adrenocorticotropic hormone; BMI, body mass index. 
Table 2 Plasma ACTH and cortisol levels in subjects with and without MS in positive and negative family history of T2DM categories

\begin{tabular}{|c|c|c|c|c|c|c|}
\hline & \multicolumn{3}{|c|}{ Subjects with family history of T2DM } & \multicolumn{3}{|c|}{ Subjects without family history of T2DM } \\
\hline & MS & No MS & $P$ value & MS & No MS & $P$ value \\
\hline $\mathrm{n}$ & 50 & 228 & - & 27 & 190 & - \\
\hline Males (\%) & $27(54)$ & $133(58)$ & 0.575 & $19(70)$ & $126(66)$ & 0.675 \\
\hline Age & $35.2 \pm 10.5$ & $21.8 \pm 8.6$ & $<0.001$ & $34.2 \pm 8.2$ & $28.3 \pm 8.5$ & 0.001 \\
\hline BMI & $28.9 \pm 4.37$ & $22.4 \pm 5.3$ & $<0.001$ & $25.4 \pm 2.4$ & $21.6 \pm 3.5$ & $<0.001$ \\
\hline $\mathrm{ACTH}^{\mathrm{a}}$ & $19.7 \pm 13.9$ & $23.7 \pm 20$ & 0.211 & $29.0 \pm 23$ & $26.5 \pm 22.2$ & 0.840 \\
\hline Cortisol $^{\mathrm{a}}$ & $9.6 \pm 4.2$ & $1 \mathrm{I} . \mathrm{I} \pm 4.8$ & 0.045 & $11.3 \pm 4.8$ & $11.8 \pm 5.0$ & 0.423 \\
\hline
\end{tabular}

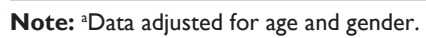

Abbreviations: ACTH, adrenocorticotropic hormone; BMI, body mass index; MS, metabolic syndrome; T2DM, type 2 diabetes mellitus.

insulinogenic index (0-30, IGI 30), and positively correlated with HDL-cholesterol. After adjusting for BMI, cortisol was positively correlated with HDL-cholesterol and negatively correlated with IGI 30. In females, cortisol was positively correlated with fasting glucose and systolic blood pressure. The significance persisted even after adjusting for BMI (Table 3).

In males, after adjusting for age and BMI, ACTH levels positively correlated with fasting glucose $(r=0.15, P=0.02)$ and HDL-cholesterol $(r=0.13, P=0.03)$ and negatively correlated with IGI $30(r=-0.149, P=0.02)$. In females, ACTH was correlated with fasting glucose $(r=0.22, P=0.002)$ and systolic $(r=0.17, P=0.02)$ and diastolic blood pressure $(r=0.27, P<0.001)$.

\section{Discussion}

We observed opposing effects of obesity and fasting glucose on morning plasma cortisol levels. Cortisol was lower in obese than normal-weight subjects in each fasting glucose category. In normal-weight MS subjects, cortisol levels were similar to those of normal-weight controls, but obese MS subjects had lower cortisol. Subjects with MS and a family history of T2DM had significantly lower cortisol and higher BMI. There was gender-specific association of morning cortisol with MS components. In males, cortisol was positively correlated with HDL-cholesterol and negatively with WC and IGI 30. In females, cortisol levels were positively correlated with systolic blood pressure and fasting glucose.

Anagnostis et al observed that patients with MS showed hyperactivity of the hypothalamic-pituitary-adrenal (HPA) axis, which lead to a state of "functional hypercortisolism." " The cause of this activation of the HPA axis remains uncertain; it could be related to chronic stress, low birth weight, or a variety of other factors. ${ }^{4}$ Reinehr and Andler observed that cortisol levels were moderately elevated in

Table 3 Correlation of morning cortisol with metabolic syndrome-related risk factors in males and females

\begin{tabular}{|c|c|c|c|c|c|c|c|c|}
\hline & \multicolumn{4}{|l|}{$\begin{array}{l}\text { Males } \\
\mathrm{n}=\mathbf{3 0 5}\end{array}$} & \multicolumn{4}{|c|}{$\begin{array}{l}\text { Females } \\
n=190\end{array}$} \\
\hline & \multicolumn{2}{|c|}{ Adjusted for age } & \multicolumn{2}{|c|}{$\begin{array}{l}\text { Adjusted for age } \\
\text { and BMI }\end{array}$} & \multicolumn{2}{|c|}{ Adjusted for age } & \multicolumn{2}{|c|}{$\begin{array}{l}\text { Adjusted for age } \\
\text { and BMI }\end{array}$} \\
\hline & $r$ value & $P$ value & $r$ value & $P$ value & $r$ value & $P$ value & $r$ value & $P$ value \\
\hline WC (cm) & -0.12 & $0.03 *$ & & & -0.05 & 0.46 & & \\
\hline Waist to hip ratio & -0.07 & 0.2 & 0.02 & 0.76 & -0.06 & 0.25 & -0.06 & 0.38 \\
\hline Fasting insulin $(\mu \mathrm{IU} / \mathrm{mL})$ & -0.139 & $0.015^{*}$ & -0.04 & 0.45 & -0.02 & 0.81 & -0.01 & 0.84 \\
\hline Fasting glucose (mg/dL) & -0.003 & 0.95 & 0.02 & 0.71 & 0.15 & $0.04^{*}$ & 0.15 & $0.03^{*}$ \\
\hline HOMA-IR $(\mu \mathrm{U} / \mathrm{mL}, \mathrm{mmol} / \mathrm{l})$ & -0.133 & $0.02 *$ & -0.04 & 0.50 & 0.01 & 0.94 & 0.01 & 0.83 \\
\hline IGI $30(\mathrm{nmol} / \mathrm{mmol})$ & -0.198 & 0.001 & -0.156 & $0.009 *$ & 0.02 & 0.78 & 0.02 & 0.78 \\
\hline $\mathrm{TG}(\mathrm{mg} / \mathrm{dL})$ & 0.061 & 0.29 & 0.11 & 0.06 & -0.01 & 0.84 & -0.01 & 0.86 \\
\hline Total cholesterol (mg/dL) & 0.054 & 0.35 & 0.09 & 0.09 & 0.10 & 0.15 & 0.10 & 0.14 \\
\hline HDL-cholesterol (mg/dL) & 0.149 & $0.01 *$ & 0.12 & $0.04^{*}$ & 0.09 & 0.19 & 0.10 & 0.17 \\
\hline LDL-cholesterol (mg/dL) & -0.012 & 0.82 & 0.02 & 0.71 & 0.09 & 0.21 & 0.09 & 0.21 \\
\hline Systolic BP (mmHg) & -0.04 & 0.52 & 0.01 & 0.76 & 0.15 & $0.05^{*}$ & 0.15 & $0.04 *$ \\
\hline Diastolic BP (mmHg) & -0.04 & 0.52 & 0.02 & 0.66 & 0.12 & 0.11 & 0.12 & 0.11 \\
\hline
\end{tabular}

Note: *Significant $P<0.05$.

Abbreviations: ACTH, adrenocorticotropic hormone; BMI, body mass index; BP, blood pressure; HOMA-IR, homeostasis model assessment-insulin resistance; IGI 30, insulinogenic index (0-30); HDL-cholesterol, high-density lipoprotein cholesterol; LDL-cholesterol, low-density lipoprotein cholesterol; MS, metabolic syndrome; T2DM, type 2 diabetes mellitus; TG, triglycerides; WC, waist circumference. 
obese insulin-resistant subjects. A reduction in cortisol with weight loss has been reported. ${ }^{19}$ Our observation of lower plasma cortisol in obese subjects is in agreement with that of Travison et al who observed lower plasma cortisol in obese subjects than in lean subjects. ${ }^{20}$ Phillips et al also observed higher plasma cortisol concentrations associated with older age and lower BMI, in 50- to 70-year-old men. ${ }^{21}$ Higher systolic blood pressure, fasting glucose, and fasting TG concentrations and insulin resistance were also related to higher cortisol. ${ }^{21}$ Weigensberg et al observed higher morning serum cortisol in overweight Latino youths with MS. Subjects with impaired fasting glucose had significantly higher morning cortisol than those with normal fasting glucose. They found no relationship between cortisol and WC. ${ }^{6}$ Ward et al, in a study conducted on a South Indian population, reported that high fasting cortisol levels were significantly associated with components of MS such as fasting glucose, systolic and diastolic blood pressure, insulin resistance, and fasting TG levels. ${ }^{22}$

The MONICA (Monitoring of Trends and Determinants in Cardiovascular Disease) study in northern Sweden showed that increasing obesity and plasma cortisol make independent and gender-specific contributions to variations in blood pressure and other cardiovascular risk factors..$^{23}$ It was observed that the association of plasma cortisol with blood pressure was stronger in men and the association with other features such as hyperinsulinemia and hypertriglyceridemia was stronger in women. ${ }^{23}$ However, we did not observe such a pattern. We observed stronger correlation of cortisol with serum TG and fasting insulin in men and between cortisol and systolic blood pressure in women.

The cause-effect relationship of obesity and cortisol is not clearly known. Studies that used a 24-hour urine cortisol or stimulated cortisol measurement have reported higher cortisol secretion in obesity. ${ }^{24,25}$ This may be due to an altered HPA axis in obesity, resulting in a blunted diurnal variation in cortisol levels, with lower morning cortisol and higher evening cortisol. ${ }^{26}$ Another explanation of lower morning cortisol could be the enhanced metabolic clearance of cortisol in obesity, which is compensated for only partly by enhanced cortisol secretion. ${ }^{10}$

The main limitation of the present study is that it is a single morning cortisol measurement. The cause-effect relationship of cortisol with obesity and other related parameters cannot be deduced from a cross-sectional study. In summary, we observed opposing effects of obesity and fasting plasma glucose on morning plasma cortisol. Obese subjects had lower morning plasma cortisol than lean subjects. Subjects with impaired fasting glucose had higher morning plasma cortisol than subjects with normal fasting glucose.

\section{Acknowledgments}

We acknowledge the help of Shiji Binu and Leslie James for their assistance in performing hormonal assays. Manoj Srivasthava is acknowledged for his help in recruiting participants for the study. The study was funded by the Indian Council of Medical Research.

\section{Disclosure}

The authors declare no conflicts of interest in relation to this paper.

\section{References}

1. van Raalte DH, Ouwens DM, Diamant M. Novel insights into glucocorticoid-mediated diabetogenic effects: towards expansion of therapeutic options? Eur J Clin Invest. 2009;39(2):81-93.

2. Purnell JQ, Kahn SE, Samuels MH, Brandon D, Loriaux DL, Brunzell JD. Enhanced cortisol production rates, free cortisol, and 11 beta-HSD-1 expression correlate with visceral fat and insulin resistance in men: effect of weight loss. Am J Physiol Endocrinol Metab. 2009;296(2):E351-E357.

3. Walker BR. Cortisol-cause and cure for metabolic syndrome? Diabet Med. 2006;23(12):1281-1288.

4. Anagnostis P, Athyros VG, Tziomalos K, Karagiannis A, Mikhailidis DP Clinical review: The pathogenetic role of cortisol in the metabolic syndrome: a hypothesis. J Clin Endocrinol Metab. 2009;94(8): 2692-2701.

5. Sen Y, Aygun D, Yilmaz E, Ayar A. Children and adolescents with obesity and the metabolic syndrome have high circulating cortisol levels. Neuro Endocrinol Lett. 2008;29(1):141-145.

6. Weigensberg MJ, Toledo-Corral CM, Goran MI. Association between the metabolic syndrome and serum cortisol in overweight Latino youth. J Clin Endocrinol Metab. 2008;93(4):1372-1378.

7. Duclos M, Marquez Pereira P, Barat P, Gatta B, Roger P. Increased cortisol bioavailability, abdominal obesity, and the metabolic syndrome in obese women. Obes Res. 2005;13(7):1157-1166.

8. Rosmond R, Dallman MF, Björntorp P. Stress-related cortisol secretion in men: relationships with abdominal obesity and endocrine, metabolic and hemodynamic abnormalities. J Clin Endocrinol Metab. 1998;83(6):1853-1859.

9. Epel ES, McEwen B, Seeman T, et al. Stress and body shape: stressinduced cortisol secretion is consistently greater among women with central fat. Psychosom Med. 2000;62(5):623-632.

10. Andrew R, Phillips DI, Walker BR. Obesity and gender influence cortisol secretion and metabolism in man. $J$ Clin Endocrinol Metab. 1998;83(5):1806-1809.

11. Reynolds RM, Walker BR, Syddall HE, Whorwood CB, Wood PJ, Phillips DI. Elevated plasma cortisol in glucose-intolerant men differences in responses to glucose and habituation to venepuncture. J Clin Endocrinol Metab. 2001;86(3):1149-1153.

12. Praveen EP, Kulshreshtha B, Khurana ML, et al. Obesity and metabolic abnormalities in offspring of subjects with diabetes mellitus. Diabetes Technol Ther. 2010;12(9):723-730.

13. Zimmet P, Alberti G, Kaufman F, et al; International Diabetes Federation Task Force on Epidemiology and Prevention of Diabetes. The metabolic syndrome in children and adolescents. Lancet. 2007; 369(9598):2059-2061. 
14. Diagnosis and classification of diabetes mellitus. Diabetes Care. 2004;27(Suppl 1):S5-S10.

15. Cole T J, Bellizzi MC, Flegal KM, Dietz WH. Establishing a standard definition for child overweight and obesity worldwide: International survey. BMJ. 2000;320(7244):1240-1243.

16. Alberti KG, Zimmet P, Shaw J; IDF Epidemiology Task Force Consensus Group. The metabolic syndrome - a new worldwide definition. Lancet. 2005;366(9491):1059-1062.

17. Tai MM. A mathematical model for the determination of total area under glucose tolerance and other metabolic curves. Diabetes Care. 1994;17(2):152-154.

18. Matthews DR, Hosker JP, Rudenski AS, Naylor BA, Treacher DF, Turner RC. Homeostasis model assessment: insulin resistance and betacell function from fasting plasma glucose and insulin concentrations in man. Diabetologia. 1985;28(7):412-419.

19. Reinehr T, Andler W. Cortisol and its relation to insulin resistance before and after weight loss in obese children. Horm Res. 2004; 62(3):107-112.

20. Travison TG, O'Donnell AB, Araujo AB, Matsumoto AM, McKinlay JB. Cortisol levels and measures of body composition in middle-aged and older men. Clin Endocrinol (Oxf). 2007;67(1):71-77.
21. Phillips DI, Barker DJ, Fall CH, et al. Elevated plasma cortisol concentrations: a link between low birth weight and the insulin resistance syndrome? J Clin Endocrinol Metab. 1998;83(3):757-760.

22. Ward AM, Fall CH, Stein CE, et al. Cortisol and the metabolic syndrome in South Asians. Clin Endocrinol (Oxf). 2003;58(4):500-505.

23. Walker BR, Soderberg S, Lindahl B, Olsson T. Independent effects of obesity and cortisol in predicting cardiovascular risk factors in men and women. J Intern Med. 2000;247(2):198-204.

24. Strain GW, Zumoff B, Kream J, Strain JJ, Levin J, Fukushima D. Sex difference in the influence of obesity on the $24 \mathrm{hr}$ mean plasma concentration of cortisol. Metabolism. 1982;31(3):209-212.

25. Pasquali R, Cantobelli S, Casimirri F, et al. The hypothalamicpituitary-adrenal axis in obese women with different patterns of body fat distribution. J Clin Endocrinol Metab. 1993;77(2):341-346.

26. Rosmond R, Dallman MF, Björntorp P. Stress-related cortisol secretion in men: relationships with abdominal obesity and endocrine, metabolic and hemodynamic abnormalities. J Clin Endocrinol Metab. 1998;83(6):1853-1859.

\section{Publish your work in this journal}

Diabetes, Metabolic Syndrome and Obesity: Targets and Therapy is an international, peer-reviewed open-access journal committed to the rapid publication of the latest laboratory and clinical findings in the fields of diabetes, metabolic syndrome and obesity research. Original research, review, case reports, hypothesis formation, expert opinion and commentaries are all considered for publication. The manuscript management system is completely online and includes a very quick and fair peer-review system, which is all easy to use. Visit http://www.dovepress.com/testimonials.php to read real quotes from published authors.

Submit your manuscript here: http://www.dovepress.com/diabetes-metabolic-syndrome-and-obesity-targets-and-therapy-journal 